\title{
Hypogonadotropic-hypogonadism (Kallman Syndrome) in Young Adult
}

\author{
Totaganti $\mathrm{M}^{1}$, Sharma $\mathrm{D}^{2}$, Ravi kant ${ }^{3}$ \\ ${ }^{1}$ Junior Resident, ${ }^{2}$ Senior Resident, ${ }^{3}$ Addl. Prof. \& Head, Div. of Diabetes and Metabolism, AIIMS \\ Rishikesh
}

\begin{abstract}
Background: Kallmann syndrome (KS) is a rare disorder first described in 1856 and later studied by Kallmann in $1944^{(1)}$. It is now designated as olfactogenital dysplasia with an association between agenesis of the olfactory bulbs and hypogonadism. The prevalence of KS is still unknown. The reported incidence is 1 in 8000 to 1 in 10000 in men and rare in women ${ }^{(2)}$. More than 24 genes are underlying KS that have been identified ${ }^{(3)}$. Mutations in these genes are thought to interfere with the expression of cell markers that guide migrating neurons, leading to failed migration of $\mathrm{GnRH}$ neurons and olfactory neurons to the forebrain during fetal development. The main clinical characteristics of KS include hypogonadotropic hypogonadism and anosmia or hyposmia. Less common phenotypes include cardiovascular anomalies, unilateral renal agenesis, cleft palate and cleft lip, cryptorchidism and osteoporosis ${ }^{(4)}$. Magnetic resonance imaging (MRI) can show abnormalities of the olfactory system and other forebrain structures ${ }^{(5)}$. Other exceptions may be discovered using MRI because of its high resolution and multiplanar capabilities, such as pituitary abnormalities ${ }^{(6)}$.
\end{abstract}

Key words: Hypogonadotropic-hypogonadism, Kallmann syndrome, olfactogenital dysplasia.

\section{Case Presentation}

An 18-year-old male patient presented to our hospital with complaints of childish voice. He was born to a nonconsanguineous marriage, full-term normal vaginal delivery. He has three siblings, and all are healthy. At birth, micropenis was observed but took no further action. He went circumcision at the age of one year. His development was apt and passed in schools with flying colours. In high school, he was bullied by his classmates for his voice. He also noted decreased ability to smell and absent morning erections. He has no history of vision difficulty, difficulty in hearing, seizures and movement disorders. No significant family history from both parental sides.

Correspondence Author

Totaganti M, Junior Resident

Div. of Diabetes and Metabolism, AIIMS Rishikesh
On examination, his height was $160 \mathrm{~cm}$, weight of $55 \mathrm{~kg}$, arm span of $165 \mathrm{~cm}$ with the upper segment to lower segment ratio of 1.1:1. He has a high pitch voice. He has no moustache, beard, absent hair over the axilla and pubic region. He has bilaterally descended testes with a pre-pubertal size of around $1 \mathrm{~cm}$ and a penile length of $1.8 \mathrm{~cm}$. On general examination, he has pallor. His systemic examination was remarkable for the reduced smell.

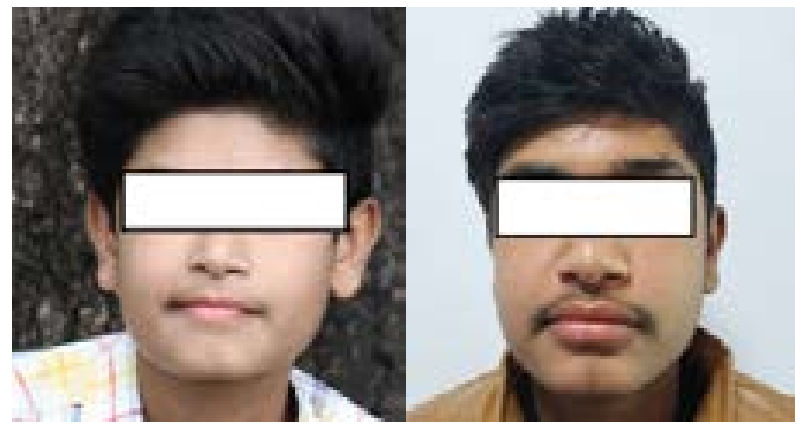

Photographs showing before treatment and after testosterone therapy 
A complete haemogram was significant for anaemia $(\mathrm{Hb}-11.5 \mathrm{gm} / \mathrm{dl})$. His serum folliclestimulating hormone (FSH), luteinizing hormone (LH), and testosterone revealed hypogonadotropic hypogonadism and tabulated below.

\begin{tabular}{|l|l|l|}
\hline \multicolumn{1}{|c|}{ Hormones } & \multicolumn{1}{|c|}{$\begin{array}{c}\text { Patient } \\
\text { values }\end{array}$} & \multicolumn{1}{c|}{ Reference range } \\
\hline Serum FSH & $0.33 \mathrm{mIU} / \mathrm{ml}$ & $1-10.5 \mathrm{mIU} / \mathrm{ml}$ \\
\hline Serum LH & $0.13 \mathrm{mIU} / \mathrm{ml}$ & $1.9-9.4 \mathrm{mIU} / \mathrm{ml}$ \\
\hline $\begin{array}{l}\text { Serum } \\
\text { testosterone }\end{array}$ & $100 \mathrm{ng} / \mathrm{Dl}$ & \\
\hline
\end{tabular}

FSH, follicle-stimulating hormone; LH, luteinizing hormone.

On Imaging, Ultrasound abdomen revealed the normal study. Scrotal ultrasound showed bilateral small testis size and volume $(2 \mathrm{ml})$. MRI brain showed hypoplastic olfactory bulbs.

The patient was started on parenteral testosterone supplements to improve his secondary sexual characters. The patient was being followed up regularly every three months. Follow up demonstrated improvement in anaemia, voice, phallic size, and development of sexual characters.

\section{Discussion}

KS is an isolated form of hypogonadotropic hypogonadism in combination with a defect in the sense of smell. Due to flaws in olfactory structures (bulbs, grooves, tracts) and altered GnRHsecreting neurons' migration into the preoptic and hypothalamic regions ${ }^{7}$. It is a genetically heterogeneous disease inherited in an X-linked, autosomal dominant or autosomal recessive pattern. The most prevalent is an X-linked form that charts to the KAL1 gene, which encodes for a neuron adhesion molecule believed to be accountable for guiding the migration of LH-releasing hormonesecreting neurons to the medial basal hypothalamus.

Our outpatient manifested with delayed puberty, characterized by high pitched voice, absence of facial and axillary hair and sparse pubic hair, micropenis and bilateral small testes. The hormonal evaluation showed low FSH, low LH and low testosterone levels. A diverse group of disorders with varied pathophysiology comprise hypogonadotropic hypogonadism or hypothalamicpituitary hypogonadism. Examples include an isolated abnormality in hypothalamic GnRH, isolated abnormality in pituitary gonadotropins (LH, FSH) and conditions in which both hypothalamic and pituitary dysfunction is present. The differential diagnosis will include KS, GnRH receptor mutation, GPR54 mutation, DAX-1 mutation and hypopituitarism ${ }^{8}$.

In this case, the diagnosis of KS is straightforward because of the hypogonadotropic hypogonadism in association with hyposmia and documented radiologic findings in MRI.

Morphological anomalies of the olfactory apparatus in KS are best evaluated with MRI. Cranial MRI, in our case, revealed a hypoplastic bilateral olfactory bulb. The pituitary gland is normal.

Clinical diagnosis of $\mathrm{KS}$ in adults is reasonably apparent, depending on the co-existence of anosmia with subnormal levels of gonadal steroid and gonadotropins. However, the diagnosis may be difficult to establish in pre-pubertal age patients who may require genetic testing and $\mathrm{MRI}^{9}$.In these patients, MRI will aid in the diagnosis of KS by demonstrating characteristic abnormalities in olfactory sulci and tracts. To diagnose $\mathrm{KS}$, infiltrative disorders and space-occupying lesions of the pituitary must be excluded. Novel researches have revealed ethmoid bone anomalies and pituitary aberrations on computed tomography in KS patients.

Therapeutic objects in the adolescent male with $\mathrm{CHH}$ are well defined: to produce virilization, to reach optimal adult height, to acquire average bone mass and body composition, to achieve normal psychosocial development, and to gain fertility. Gonadotropins are used for fertility treatments in 
adult patients with $\mathrm{CHH}$ and can also stimulate pubertal maturation in adolescent males with $\mathrm{CHH}$. An additional advantage of gonadotropin treatment compared with $\mathrm{T}$ treatment is the stimulation of testicular growth and spermatogenesis. Therefore, gonadotropin therapy may contribute to crucial psychical reassurance in teenagers and heighten self-confidence ${ }^{10}$.

In summary, we have a KS case who presented with a micropenis early in life but unfortunately was not further evaluated. He subsequently presented with eunuchoid body proportion, high pitched voice, absence of facial and axillary hair and sparse pubic hair, micropenis and bilaterally descended prepubertal testes. Associated findings were hyposmia and facial anomalies, namely congenital absence of puncta and smooth philtrum. The hormonal evaluation was consistent with hypogonadotropic hypogonadism. Cranial MRI showed aplastic right olfactory bulb and hypoplastic left olfactory bulb.

\section{References}

1. Arkoncel ML, Arkoncel FR, Lantion-Ang FL. A case of Kallmann syndrome. Case Reports. 2011 Jan 1;2011:bcr0120113727.

2. Dzemaili S, Tiemensma J, Quinton R, Pitteloud $\mathrm{N}$, Morin D, Dwyer AA. Beyond hormone replacement: quality of life in women with congenital hypogonadotropic hypogonadism. Endocrine Connections. 2017 Aug 1;6(6):40412.

3. Vezzoli V, Duminuco P, Bassi I, Guizzardi F, Persani L, Bonomi M. The complex genetic basis of congenital hypogonadotropic hypogonadism. Minerva endocrinologica. 2016 Mar 2;41(2):223-39.
4. Boehm U, Bouloux PM, Dattani MT, De Roux N, Dodé C, Dunkel L, Dwyer AA, Giacobini P, Hardelin JP, Juul A, Maghnie M. Expert consensus document: European Consensus Statement on congenital hypogonadotropic hypogonadism-pathogenesis, diagnosis and treatment. Nature Reviews Endocrinology. 2015 Sep;11(9):547.

5. Zhang Z, Sun X, Wang C, Wang G, Zhao $B$. Magnetic resonance imaging findings in Kallmann syndrome: 14 cases and review of the literature. Journal of Computer Assisted Tomography. 2016 Jan 1;40(1):39-42.

6. Bolu SE, Tasar M, Üçkaya G, Gönül E, Deniz F, Özdemir IÇ. It increased abnormal pituitary findings on magnetic resonance in patients with male idiopathic hypogonadotropic hypogonadism. Journal of endocrinological investigation. 2004 Dec;27(11):1029-33.

7. Salama N. Kallmann syndrome and deafness: an uncommon combination: A case report and a literature review. International Journal of Reproductive BioMedicine. 2016 Aug;14(8):541.

8. DeGroot LJ, Jameson JL. Endocrinology. Vol. 2.

9. Madan R, Sawlani V, Gupta S, Phadke RV. MRI findings in Kallmann syndrome.

10. Young J, Xu C, Papadakis GE, Acierno JS, Maione L, Hietamäki J, Raivio T, Pitteloud N. Clinical management of congenital hypogonadotropic hypogonadism. Endocrine reviews. 2019 Apr;40(2):669-710. 